\title{
The Development Mode of Campus Culture in Chinese Undergraduate Universities
}

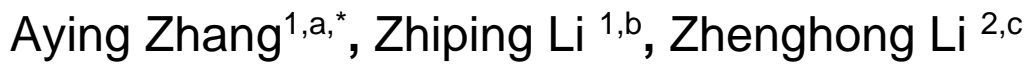 \\ ${ }^{1}$ Harbin University, 150086 Harbin, China \\ ${ }^{2}$ Harbin Institute of Technology, 150001 Harbin, China \\ a,*zaying@sina.com, blizp2008@126.com, c273662999@qq.com
}

Keywords: Development model, Campus culture, Undergraduate, Universities.

\begin{abstract}
The undergraduate university culture is a cultural system formed by undergraduates in the process of inheriting, collating, exchanging and innovating knowledge, which is related to and different from popular culture or other social culture. The culture of undergraduate universities is formed in the long-term running process of undergraduate universities, which takes undergraduate universities as the carrier, takes undergraduate students as the main body, and takes knowledge and discipline as the cultural form of undergraduate universities. The structure of undergraduate university culture mainly includes spiritual culture, institutional culture and material culture. The function of undergraduate university culture mainly includes inheriting culture, innovating culture and spreading culture. The characteristics of undergraduate university culture mainly include historicity and inheritance, openness and innovation, scientificity and tolerance, modernity and criticism, advancement and forerunner.
\end{abstract}

\section{Related concepts of undergraduate university culture}

\subsection{The definition of undergraduate university culture}

\subsubsection{Systematics perspective}

From a systematic point of view, undergraduate university culture is a cultural system formed by undergraduates in the process of inheriting, collating, exchanging and innovating knowledge, which is related to and different from popular culture or other social culture.

\subsubsection{Culturology perspective}

From the cultural point of view, the undergraduate university culture is a kind of sub-culture, which is a set of values, behavior, language habits, system, knowledge symbols, and architectural style set up around the undergraduate university education and teaching activities.

\subsubsection{Education perspective}

From the pedagogical point of view, the undergraduate university culture refers to the higher education culture, its existence scope is limited to the undergraduate university campus, its population is limited to the undergraduate university teachers and students' staff, its manifestation is only reflected in the undergraduate university education, teaching and other activities.

1.1.4 Histology perspective

From the perspective of histology, undergraduate university culture is a unique organizational culture based on knowledge and discipline settings.

\subsection{The structure of undergraduate university culture}

There are dichotomy structure theory, three-part structure theory, four-part structure theory, five-part structure theory and eight-part structure theory in the culture of undergraduate universities.

Among them, the dichotomy structure is scientific culture and humanistic culture; the trichotomy structure is spiritual culture, institutional culture and material culture. 
Quadripartite structure is spiritual culture, institutional culture, material culture, environmental culture, or spiritual culture, institutional culture, behavioral culture, environmental culture, or spiritual culture, institutional culture, material culture, behavioral culture.

Five-point structure theory is the value concept and its university spirit, University image, development goals, rules and regulations and University environment.

The octave structure theory is a broad and beautiful campus, a culture full of critical spirit, a culture based on people, an academic-centered culture, a pluralistic culture, an open culture, an advanced culture, and a culture of wisdom.

\subsection{Functions of undergraduate university culture}

The undergraduate university culture has four functions, five functions and six functions. Among them, the four-function theory has four functions, including inheriting culture, innovating culture, researching culture and integrating culture.

The theory of five functions is that undergraduate university culture has five functions: guiding function, stimulating function, standardizing function, edifying function and identifying function. It includes the consciousness and tradition of pursuing truth, the noble consciousness and spirit, the ideal consciousness and spirit, the consciousness and realm of social responsibility, the consciousness and tradition of civilization and progress. Or value orientation, behavior restraint, sentiment edification, psychological factor construction, collective cohesion and other five functions.

The theory of six functions is that the culture of undergraduate universities has a scientific attitude of seeking truth from facts, an equal and tolerant spirit of compatibility, a concern for humanity, a free pursuit of self-transcendence, a national complex with a broad view of the world, and a critical spirit based on reality.

\subsection{Characteristics of undergraduate university culture}

The undergraduate university culture has five characteristics, seven characteristics, eight characteristics and nine characteristics. Among them, the theory of five characteristics is that the culture of undergraduate universities has five characteristics: sacredness, idealism, academics, criticism and tradition.

The theory of seven characteristics is that the culture of undergraduate universities has seven characteristics, including ideological, innovative, national, open, tolerant, learning and modernity.

Eight characteristics say that undergraduate university culture has eight characteristics, including historicity, incompleteness, inheritance, innovation, conservatism, openness, internationality and locality.

The theory of the nine characteristics is that the culture of undergraduate universities has nine characteristics, including multi-subjectivity, cultural forerunner, and high consciousness, advanced thought, serving the masses, rationality, scientificity, openness and creativity.

We believe the culture of undergraduate universities is formed in the long-term running process of undergraduate universities, which takes undergraduate universities as the carrier, takes undergraduate students as the main body, and takes knowledge and discipline as the cultural form of undergraduate universities including basis, take university ideas and university spirit as the core, values, thinking habits, behavior, institutional system, knowledge symbols, architectural style.

The structure of undergraduate university culture mainly includes spiritual culture, institutional culture and material culture. The function of undergraduate university culture mainly includes inheriting culture, innovating culture and spreading culture.

The characteristics of undergraduate university culture mainly include historicity and inheritance, openness and innovation, scientificity and tolerance, modernity and criticism, advancement and forerunner. 


\section{Cultural connotation of undergraduate universities}

\subsection{The "body" and "form" of undergraduate university culture}

The culture of undergraduate universities is a whole, which can be divided into three levels, including spiritual culture, institutional culture and material culture. Among them, spiritual culture is the guide, material culture is the foundation, and institutional culture is the backbone. Each level of culture has two levels of "body" and "form".

The "body" of the spiritual culture of undergraduate universities is the idea (thought), the strategy (goal) and the characteristic (advantage) of running a school. The "form" of the spiritual culture of undergraduate universities is the ideological method and thinking mode of forming these ideas (thought), the strategy (goal) and the characteristic (advantage) of running a school.

Similarly, the "body" of the institutional culture of undergraduate universities is the institutional framework, operating mechanism, rules and regulations, etc. The "form" of the institutional culture of undergraduate universities is the ideological method and thinking mode of forming these educational systems and mechanisms.

The "body" of material culture in undergraduate universities is subject specialty, faculty, and infrastructure, and so on. The "form" of material culture in undergraduate universities is the ideological method and thinking mode to form these disciplines, faculty and infrastructure.

\subsection{The "body" and "form" of undergraduate university culture connotation}

\subsubsection{Spiritual culture of undergraduate universities}

The spiritual culture of undergraduate universities is mainly based on the profound understanding of historical traditions, educational laws and the trend of the times, and the understanding and grasp of the orientation, ideas, objectives, traditions and strategies of running a university.

The "form" of undergraduate university's spiritual culture is the ideological method and thinking mode in the process of forming undergraduate university's school-running ideas (thoughts), school-running strategies (goals), and school-running characteristics (advantages) and so on.

The spiritual and cultural "body" of undergraduate universities refers to the ideas, strategies and advantages of running a university. Therefore, the spiritual and cultural connotation of undergraduate universities refers to the ideas (ideas), strategies (objectives), characteristics (advantages) and other contents formed in the process of running a university, as well as the ideological methods and thinking modes of forming these ideas (ideas), strategies (objectives) and characteristics (advantages) of running a university.

\subsubsection{Institutional culture of undergraduate universities}

The institutional culture of undergraduate universities mainly refers to the laws, regulations and related regulations, regulations and management systems that maintain the internal operation of universities and the relationship between universities and the outside world.

Such as teaching management system, personnel management system, campus management system, enrollment system, teacher code, student code, post responsibility system, work and rest system, etc. Thirdly, the school rules and regulations, organizational structure, operation mechanism and behavior norms of teachers and students embody the school-running concept. Therefore, the "form" of the institutional culture of undergraduate universities is the system structure, operation mechanism, rules and regulations, etc.

The "shape" of the institutional culture of undergraduate universities is the ideological method and thinking mode that forms these institutional frameworks, operational mechanisms, rules and regulations. Therefore, the connotation of institutional culture of undergraduate universities refers to the institutional framework, operational mechanism, rules and regulations formed in the process of running a university, as well as the ideological method and thinking mode of forming these institutional framework, operational mechanism, rules and regulations. 


\subsubsection{Material culture of undergraduate universities}

Material culture of undergraduate universities mainly refers to the high-level professional disciplines and faculty, modern libraries and laboratories (training bases) and campus networks. The material culture of undergraduate universities is discipline, teaching staff, infrastructure and so on.

The "shape" of the material culture of undergraduate universities is the way of thinking and thinking that forms these disciplines, majors, teaching staff, infrastructure, etc. Therefore, the material and cultural connotations of undergraduate universities refer to the contents of discipline, faculty, infrastructure, etc. formed in the course of running a university, as well as the ideological method and thinking mode of forming these disciplines, faculty and infrastructure.

\section{Strategies for developing campus culture in undergraduate universities}

\subsection{Strategies for the development of spiritual culture in undergraduate universities}

The spiritual culture of undergraduate universities refers to the ideas (ideas), strategies (objectives), characteristics (advantages) and other contents formed in the process of running a university, as well as the ideological methods and thinking modes of forming these ideas (thoughts), strategies (objectives) and characteristics (advantages) of running a university.

\subsection{Strategies for the institutional culture development of undergraduate universities}

The institutional culture of undergraduate universities refers to the system structure, operation mechanism, rules and regulations formed in the course of running a university, as well as the ideological method and thinking mode of forming this system structure, operation mechanism, rules and regulations. The functions of undergraduate universities are personnel training; scientific research and so on, that is, and undergraduate universities are academic institutions. The governing bodies of academic institutions are academic committees (professors' associations) and so on. The operating mechanism is to reach a consensus through peer review and discussion.

\subsection{Strategies for the development of spiritual culture in undergraduate universities}

Material culture of undergraduate universities refers to the contents of discipline, faculty, infrastructure, etc. formed in the course of running a university, as well as the ideological method and thinking mode of forming these disciplines, faculty and infrastructure.

Subject specialty is the carrier of realizing the functions of talent cultivation, scientific research and social service in undergraduate universities. Its goal is to cultivate high-quality professional talents and research achievements.

\section{Acknowledgement}

This research was financially supported by Heilongjiang Social Science Foundation (Grant No. 17SHD204).

\section{References}

[1] Z. P. Li, W. D. Wu: China Higher Education Research vol. 6 (2005), pp. 39

[2] Z. P. Li, W. D. Wu: China Higher Education Research vol. 7 (2006), pp. 56

[3] Z. P. Li, H. B. Zhang and et al: Heilongjiang Researches on Higher Education vol. 10 (2006), pp. 77

[4] Z. P. Li: Heilongjiang Researches on Higher Education vol. 3 (2005), pp. 22

[5] Z. P. Li: Education Exploration vol. 4 (2005), pp. 38

[6] Z. P. Li and et al: Journal of Harbin University vol. 10 (2005), pp. 64 